\title{
A Rare Case of Rupture Cornual Ectopic Pregnancy with Late Diagnosis
}

\author{
Dr. Adusumilli Padmaja ${ }^{1}$ (Assistant Professor) \\ Dr. Prashanthi Vemulapalli ${ }^{2}$ (Sr. Registrar) \\ Dr. Usha $\mathrm{Nag}^{3}$ (Associate Professor) \\ 1, 2,3 (Dept. of OBG, Dr. PSIMS \& RF, Chinoutpalli, AP, India)
}

\begin{abstract}
Cornual ectopic pregnancy remains a rarity among ectopic pregnancies with higher mortality rates due to rupture \& late diagnosis. We are reporting a case of rupture cornual ectopic pregnancy, with no risk factors identified \& a delayed presentation. Patient presented with complaints of pain abdomen and vomiting \& syncopal attacks of 4 days duration. Case was diagnosed using bedside USG. Emergency laparotomy was done $\&$ left ruptured cornual ectopic pregnancy was seen with hemoperitoneum. Left salpingectomy was done. Case was revived with 4 units of intra \& post op transfusions. This is to emphasize that all women in reproductive age group with symptoms least suggestive of ectopic pregnancies should be evaluated until proved otherwise \& the suspicion for ectopic pregnancy be continued.
\end{abstract}

Key words: Cornual ectopic pregnancy, low risk group, institutional care, mortality.

\section{Introduction}

The incidence of cornual ectopic pregnancy is $2-4 \%^{1}$ of the ectopic pregnancies with a mortality rate 7 times higher than other ectopic pregnancies. The aim of presenting this case report is to emphasize, that ectopic pregnancy is seen in women of low risk category also. Cornual ectopic pregnancy is least common among ectopic pregnancies but has catastrophic consequences due to rupture \& late diagnosis ${ }^{2} \&$ therefore needs an institutional care. It is the suspicion of ectopic pregnancy that leads to early diagnosis.

\section{Case Report}

Mrs X aged 30 years belonging to a low socioeconomic group was brought to Dr. PSIMS \& RF with pain abdomen of 4 days duration and vomiting and syncopal attacks of 2 days duration. She was married for 6 months; nulligravida not used any contraceptive methods. Her PMC were regular \& LMP was one month back. Patient had taken treatment from her local place where she was treated with analgesics \& IV fluids for 2 days. Patient was referred in view of her deteriorating general condition \& continuing symptoms.

On examination: Despite the severe degree of pallor patient was stable PR: 104/min, BP: 90/60 mm $\mathrm{Hg}$, CVS, RS normal, P/A tenderness was present all over her abdomen. P/S - Cx \& vagina were healthy. On bimanual examination uterine size and position could not made out due to tenderness. Fullness was felt in left fornix.

Urine pregnancy test was positive. Bed side USG revealed: uterus 6.4 x $4.7 \times 3.5 \mathrm{~cm}$. endometrial thickness $-14 \mathrm{~mm}$. Rt ovary $3.1 \times 1.6 \mathrm{~cm}$, Lt ovary 3.0 × $1.8 \mathrm{~cm}$, irregular echogenic lesion of $10.3 \times 8.5 \times 5.8$ was noted in POD probably a hematoma. Gestational sac with embryo with CRL corresponding to 8 wks gestation was noted within the haematoma. Her blood investigations were sent $\mathrm{Hb}-4 \mathrm{gm} \%$, B positive, serology screen negative.

Emergency laparotomy was done in view of ruptured ectopic pregnancy intraoperative findings were: 1 lt of hemoperitoneum was present with clots weighing $500 \mathrm{gms}$.

Gestational sac with foetus was obtained from the POD, uterus normal in size left cornual end of uterus was ruptured (severed) left salpingectomy was done, cornual end was sutured with no 1 catgut hemostatis was achieved . Rt tube \& ovary and lt ovary were normal. Peritoneal wash was given with normal saline and abdomen was closed in layers.

3 units of packed cell were transfused \& patient recovered well postoperatively.

Retrospectively history was taken there was no history suggestive of PID, or any past medical treatment suggestive of tuberculosis. 


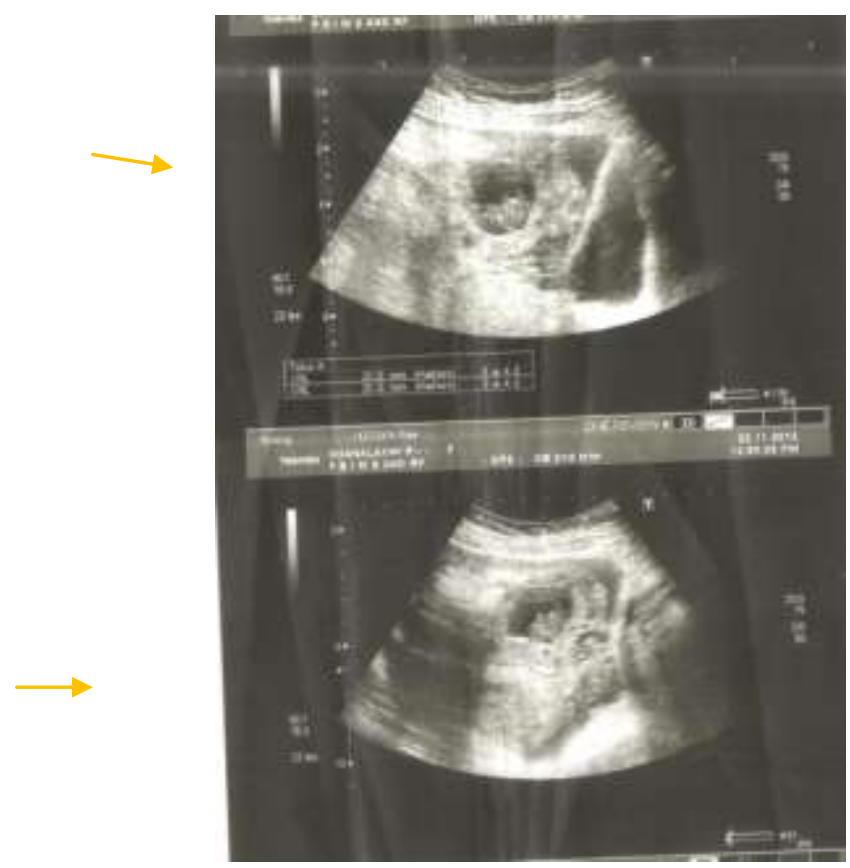

Fig 1: Ultrasound picture showing gestational sac with embryo, hemoperitoneum.

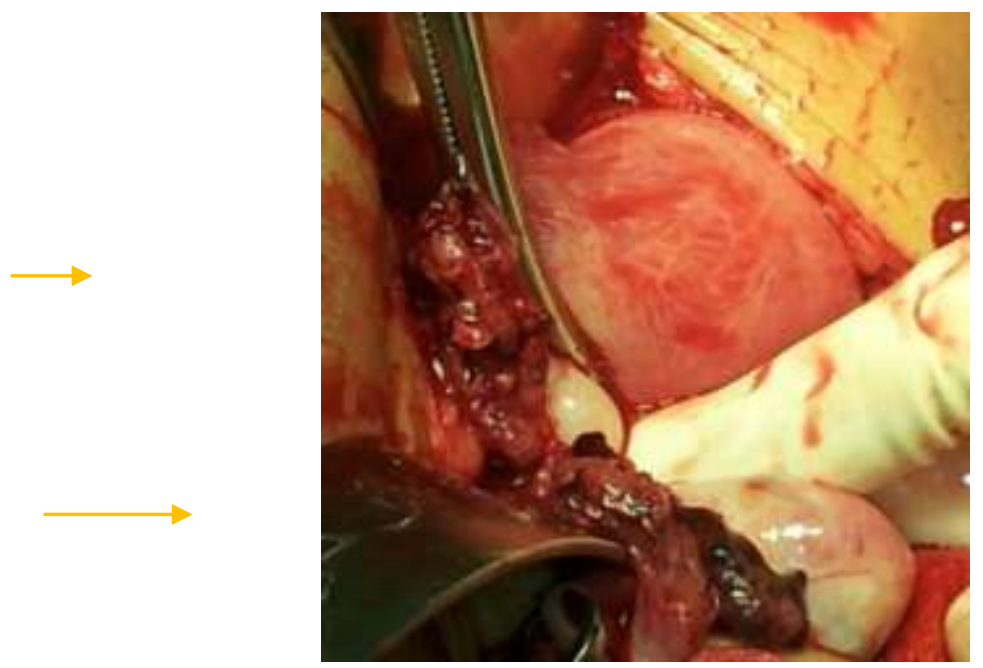

Picture showing uterus with left ruptured cornual ectopic pregnancy. Rupture site shown between the arrows.

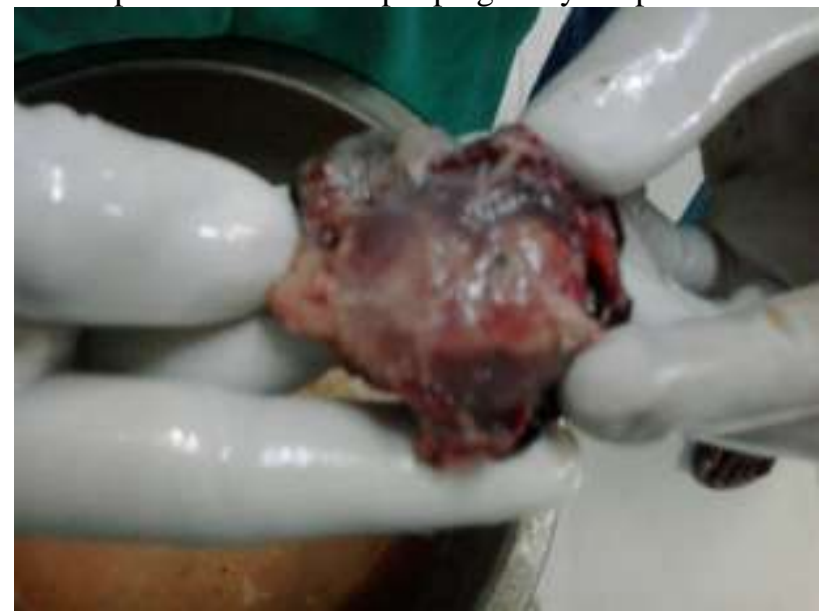

Fig 3: Picture showing fetus ensac which was obtained from POD. 


\section{Discussion}

The incidence of cornual ectopic pregnancy is $2-4 \%{ }^{1}$. Cornual ectopic pregnancy is associated with mortality rate 7 times higher than other ectopic pregnancies. Risk factors like PID, ART, contraceptive usage, tubal surgeries ${ }^{3}$ are associated with ectopic pregnancies. Cases with no risk factors can still present with ectopic pregnancy as seen in the above case.

Therefore any woman presenting in reproductive age group with even symptoms least related to ectopic pregnancy, should be investigated with a suspicion of ectopic pregnancy ${ }^{4}$. In the above case though the patient had cornual rupture and a delay in referral, patient condition was stable because there was a hematoma on cornual end which probably prevented further bleeding. Most of the women still seek medical help from rural medical practitioners. Awareness has to be created among the rural practitioners about the importance of identifying such cases \& timely referral. The rarity in the above case was, the patient could be revived despite a cornual rupture of $48-72$ hrs duration.

Symptoms of ectopic pregnancy range from being asymptomatic to state of shock ${ }^{5}$. Patient presenting with shock are easy to diagnose, however early diagnosis of women with sutle symptoms is important which is possible when the practicing doctor has a suspicion of ectopic pregnancy, and either rules it out or nails it.

[1] Williams Text book of Obstetrics $23^{\text {rd }}$ edition pg no: 239

[2] Takei T, Matsuoka S, Ashitani N, Makihara N, Morizane M, Ohara N, PMID:

[3] 19688960, [PubMed - indexed for MEDLINE]

[4] Tulandi T. Incidence, risk factors, and pathology of ectopic pregnancy. http://www.uptodate.com/index. Accessed Nov. 14, 2011.

[5] Faraj R, Steel M. Management of cornual (interstitial) pregnancy. The Obstetrician \& Gynaecologist 2007: $9: 249-255$.

[6] Brewer H, Gefroh S, Munkarah A, Hawkins R, Redman ME, J Reprod Med. 2005 Sep;50(9):715-8. 